\title{
An investigation on the attenuation effect of air pollution on regional solar
}

\section{radiation}

Chunxiao Zhang ${ }^{1}$, Chao Shen ${ }^{1}$, Qianru Yang ${ }^{1}$, Shen Wei ${ }^{2}$, Guoquan $\mathrm{Lv}^{1}$, Cheng Sun ${ }^{1}$

${ }^{1}$ School of Architecture, Harbin Institute of Technology, Key Laboratory of Cold Region Urban and Rural Human Settlement Environment Science and Technology, Ministry of Industry and Information Technology, Harbin 150090, China

${ }^{2}$ The Bartlett School of Construction and Project Management, University College London (UCL), London, WC1E 7HB, UK

*Corresponding author: chaoshen@hit.edu.cn

Abstract: Due to the continuous increase of environmental pollution in recent years, the high concentration of particulate matters in air has greatly reduced the amount of solar radiation that can reach the earth, and this reduction has a direct effect on the use of solar energy in buildings. To quantify this attenuation effect, historical meteorological data collected from five regions, namely, Beijing, Tianjin, Jinan, Xi' an and Zhengzhou, in China from 2014 to 2016 were used to investigate the correlation between clearness index (reflecting available radiation) and air quality index (reflecting pollution level). The analysis results have revealed that higher air quality index would result in lower clearness index, and the sunny days gave higher decreasing rate than cloudy days. For all five regions, their monthly clearness index attenuation showed higher values in winter than that in summer. The monthly solar radiation attenuation, however, showed an opposite trend, due to higher solar altitude in summer. Additionally, different regions had different annual solar radiation attenuation ratio, with Tianjin giving the highest of $6.56 \%\left(651.17 \mathrm{MJ} / \mathrm{m}^{2}\right)$, followed by Beijing $\left(3.92 \%, 410.08 \mathrm{MJ} / \mathrm{m}^{2}\right)$, Xi'an $\left(4.94 \%, 510.42 \mathrm{MJ} / \mathrm{m}^{2}\right)$, Zhengzhou $\left(3.99 \%, 427.64 \mathrm{MJ} / \mathrm{m}^{2}\right)$ and Jinan $\left(2.69 \%, 284.66 \mathrm{MJ} / \mathrm{m}^{2}\right)$.

Keywords: air pollution, air quality index, particulate matters, solar radiation attenuation 
a Slope of fitting linear function (dimensionless)

$|\boldsymbol{a}| \quad$ Attenuation coefficient or absolute value of $\boldsymbol{a}$ (dimensionless)

AQI Air quality index (dimensionless)

Intercept of fitting linear function (dimensionless)

High-value of the concentration limit value close to $C_{p}\left(\mu \mathrm{g} / \mathrm{m}^{3}\right.$ or $\left.\mathrm{mg} / \mathrm{m}^{3}\right)$

$\boldsymbol{C}_{\boldsymbol{p}} \quad$ Mass concentration of pollutant $\mathrm{P}\left(\mu \mathrm{g} / \mathrm{m}^{3}\right.$ or $\left.\mathrm{mg} / \mathrm{m}^{3}\right)$

$\boldsymbol{G} \quad$ Horizontal daily global solar radiation on the ground $\left(\mathrm{MJ} / \mathrm{m}^{2}\right)$

$\boldsymbol{G}_{\boldsymbol{0}} \quad$ Extraterrestrial horizontal daily global solar radiation $\left(\mathrm{MJ} / \mathrm{m}^{2}\right)$

$\boldsymbol{G}_{\boldsymbol{m}} \quad$ Monthly solar radiation attenuation $\left(\mathrm{MJ} / \mathrm{m}^{2}\right)$

$\boldsymbol{I A Q I}_{\boldsymbol{p}}$ air quality subindex of pollutant $\mathrm{P}$ (dimensionless)

$\boldsymbol{I A Q I}_{\boldsymbol{H i}}$ Individual air quality index of $B P_{H i}$ (dimensionless)

$\boldsymbol{I A Q I}_{\boldsymbol{L o}}$ Individual air quality index of $B P_{L o}$ (dimensionless)

$\boldsymbol{K}_{\boldsymbol{d}} \quad$ Daily clearness index attenuation $\left(\mathrm{MJ} / \mathrm{m}^{2}\right)$

$\boldsymbol{K}_{\boldsymbol{m}} \quad$ Monthly clearness index attenuation $\left(\mathrm{MJ} / \mathrm{m}^{2}\right)$

41 MAPE Mean absolute percent error $\frac{\sum_{1}^{n}\left|\frac{c_{i}-m_{i}}{m_{i}}\right|}{n}$ (dimensionless)

Days of a month (dimensionless)

$45 \quad S_{0} \quad$ Daily maximum possible sunshine duration (hour)

$46 \boldsymbol{\delta} \quad$ Solar declination (radian)

$47 \boldsymbol{\omega}_{\boldsymbol{s}} \quad$ Sunset hour angle (radian) 


\section{Introduction}

With the continuous growth of global population, traditional fossil energy has become insufficient to meet people's living requirements. To achieve sustainable development, it is urgent to promote the use of renewable energy [1-3]. Solar energy has become a popular renewable energy for building applications, due to their advantages like wide distribution, large reservation, free of pollution [4]. It has captured great attentions of researchers in the world, studying the transmission, conversion and utilization of solar energy $[1,5]$. In 2018 , the global capacity of solar power has reached $402 \mathrm{GW}$, according to the “Renewables Energy 2018 - Global Status Report" [6], with China, United States and Japan, ranked as the top three countries adopting solar PV power generation.

In the past two decades, the utilization of solar energy has been developed rapidly, and more attention has been paid to solar energy conversion efficiency, including electrical efficiency, thermal efficiency and exergy efficiency [7, 8]. For conversion efficiency of solar energy systems, many factors have been identified as influential, such as photovoltaic module temperature [9], dust accumulation [10], ambient temperature and wind speed [11]. Wang et al. [12] have investigated the influences of ambient temperature, cloud amount, precipitation, altitude and wind speed on the conversion efficiency of solar energy systems, and their results demonstrated that ambient temperature was the most important factor. Precipitation and wind speed, however, showed little effect. Soltani [13] experimentally compared five cooling technologies for solar photovoltaic panels, including natural cooling, water cooling, forced air cooling, $\mathrm{SiO}_{2} /$ water and $\mathrm{Fe}_{3} \mathrm{O}_{4} /$ water nanofluid cooling. The study results demonstrated that $\mathrm{SiO}_{2} /$ water nanofluids had the highest power output and efficiency. Comparing to natural cooling, which gave the lowest power output and efficiency, the power output increased by $54.29 \%$ and the efficiency increased by $3.35 \%$. Mohammad [14] has investigated the correlation between environmental factors, namely, solar radiation, mass flow rate and dust accumulation, and performance indicators of photovoltaic modules, namely solar cell temperature, output power and electrical efficiency. The results revealed that electrical efficiency decreased $0.22 \%$ with every degree increase of solar cell temperature. Additionally, when solar radiation increased by $100 \mathrm{~W} / \mathrm{m}^{2}$, energy output increased by $3.14 \mathrm{~W}$, with cell temperature raised by $3.82^{\circ} \mathrm{C}$ and electrical efficiency decreased by $0.85 \%$. Gas molecules and particulate matters in the air may also affect the efficiency of solar energy systems, due to their selective ability of absorbing and scattering solar radiation [15]. Therefore, the level of air pollution onsite may also need to be considered 
when deciding the capacity of solar energy systems.

With the fast urbanization and industrialization in China, the transition of environmental emissions has led to serious air quality issues [16, 17], which seriously hinder the transmission and transformation of solar radiation $[18,19]$. Some researchers, therefore, have investigated the correlation between air pollution and solar radiation. Liu et al. [20] have suggested that aerosol index (AI) had a strong linear relationship with solar radiation attenuation, and additionally when predicting the power of photovoltaic power generation, the inclusion of AI would significantly help to improve prediction accuracy. Based on historical data from 38 cities in China, Wang et al. [21] have discussed the impact of air pollution index (API) on sunshine duration, where they pointed out that increase of API would decrease sunshine duration. Zhao et al. [22] reported that aerosols played an important role in global solar radiation estimation, especially in heavily polluted regions. Fang et al. [23] evaluated the influence of air pollution on both global and diffuse solar radiations by support vector machine, and suggested that PM2.5, PM10 and $\mathrm{O}_{3}$ were key parameters.

The utilization of solar energy is almost dependent on the solar radiation received on the ground, so it is necessary to investigate the attenuation effect of air pollution on regional solar radiation. Although existing literature has proven that air pollution was strongly correlated with solar radiation, the impact of air pollution on solar radiation has not been quantitatively investigated. In a previous work done by the authors, the principal component analysis method has been used to identify the variation law of clearness index with air quality index, but for clear days only, with corresponding attenuation models presented [18]. In real case, however, the weather condition is very complicated, with weather like clear days, cloudy days and even rainy days. Therefore, more work is definitely needed to cover broader climatic conditions. Based on a weather classification method proposed in this study, the impact of air pollution on the attenuation of solar radiation in different weather conditions was explored.

\section{Methodology}

According to the "Report on remote sensing monitoring of China sustainable development", which was issued by the Chinese Academy of Sciences in 2016 [24], air pollution in China is very serious in the North Plain and Sichuan Basin of China, as shown in Figure 1. 


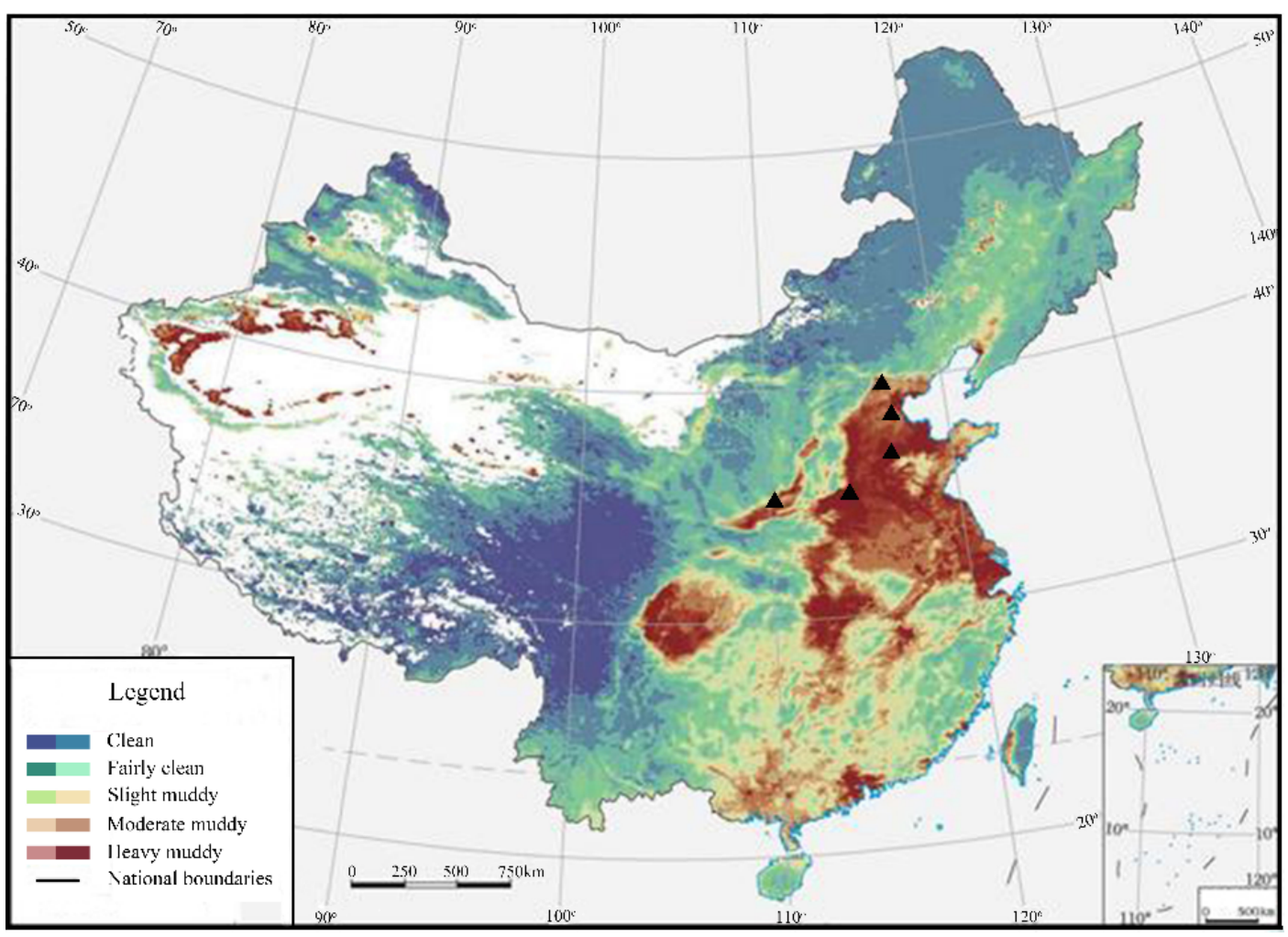

Figure 1 2010-2015 air quality distribution of China [24]

\subsection{Method}

To evaluate the attenuation effect in different weather conditions, a weather classification method is proposed in this study, using both weather factor and sunshine factor. In the method developed here, the weather levels are determined by upper atmosphere, not including particulate matters near the ground. Historical weather is recorded on the basis of cloud and rainfall, for the whole day not only on daytime, which is a rough indicator reflecting weather conditions in daytime. Meanwhile, sunshine percentage is a common indicator estimating weather levels during daytime, but collected on the ground, including the effect of particulate matters. Therefore, sunshine percentage can not be used as a critical index for judging weather levels in daytime. In this study, historical weather (called weather factor) and sunshine percentage (called sunshine factor) are combined to determine weather levels. In order to reflect weather factor (as leading role) and sunshine factor (as modified role) for evaluating historical weather levels in daytime, the weight of these two factors are given as 0.6 and 0.4 respectively, according to votes given by seven professors in solar energy research.

The classification of historical weather levels is listed in Table 1, and similar weather can be classified according to the corresponding grades.

Table 1 Historical weather levels classification 


\begin{tabular}{ccc}
\hline Weather levels & Description & Historical weather \\
\hline Level 1 & Clear days & Sunny \\
Level 2 & Partly sunny & Sunny to cloudy and partly cloudy \\
Level 3 & Cloudy & Cloudy, cloudy to light rain, sunny to cloudy, etc. \\
Level 4 & Partly overcast & Partly overcast, thunderstorm, etc. \\
Level 5 & Overcast & Overcast, light snow or medium snow, etc. \\
\hline
\end{tabular}

Sunshine percentage $\left(S / S_{0}\right)$ is the rate of sunshine duration in daytime $(\boldsymbol{S})$ to daily maximum possible sunshine duration $\left(\boldsymbol{S}_{\boldsymbol{0}}\right)$, and can be used as a supplementary factor to classify historical weather levels. Equation 1 has been used to calculate daily maximum possible sunshine duration $\left(\boldsymbol{S}_{\boldsymbol{O}}\right)$, as given in [25], where $\delta$ is solar declination and $\varphi$ is latitude.

$$
S_{0}=\frac{2}{15} \cos ^{-1}(-\tan \delta \tan \varphi)
$$

When $S / S_{0} \geq 0.8$, historical weather level is level 1. When $0.6 \leq S / S_{0}<0.8$, it is level 2. When $0.4 \leq$ $S / S_{0}<0.6$, it is level 3. When $0.2 \leq S / S_{0}<0.4$, it is level 4 , and others are level 5 .

After obtaining historical weather levels, the correlation between solar radiation and air pollution under different weather levels could be investigated. However, because horizontal global solar radiation varies with latitude, longitude and solar altitude, and changes over time. It is difficult to investigate the attenuation effect of air pollutants on solar radiation without a reference base. In this study, principal component analysis is used as a feasible solution to this question. This method can reduce the dimensionality of daily solar radiation by synthesizing multiple indicators into relevant comprehensive indicators (i.e. principal components), and each principal component can reflect main information of original variables, and this information is not duplicated.

To eliminate the influences from longitude, latitude, altitude and solar altitude angle on daily solar radiation, a dimensionless index, clearness index, was proposed to reflect solar radiation attenuation. It is the ratio of daily global solar radiation to daily extraterrestrial solar radiation on horizontal surfaces, as defined in Equation $2[25,26]$. When clearness index in polluted days is greater, solar radiation attenuation became smaller, and vice versa.

$$
K=G / G_{0}
$$

where $\boldsymbol{G}$ is daily global solar radiation on the ground $\left(\mathrm{W} / \mathrm{m}^{2}\right)$, and $\boldsymbol{G}_{\boldsymbol{o}}$ is daily extraterrestrial solar 
radiation on horizontal surfaces, calculated by Equation 3 [25],

$$
G_{0}=\frac{24}{\pi} I_{S C}\left(1+0.033 \cos \frac{360 n}{365}\right) \times\left(\cos \varphi \cos \delta \sin \omega_{s}+\frac{2 \pi \omega_{s}}{360} \sin \varphi \sin \delta\right)
$$

where $I_{S C}$ is solar constant $\left(1367 \mathrm{~W} / \mathrm{m}^{2}\right)$, with solar declination $(\delta)$ and sunset hour angle $\left(\omega_{S}\right)$ obtained by Equation 4 and Equation 5, respectively.

$$
\begin{aligned}
& \delta=23.45 \sin \left[\frac{360(n+284)}{365}\right] \\
& \omega_{s}=\cos ^{-1}(-\tan \delta \tan \varphi)
\end{aligned}
$$

According to the "Technical Regulation on Ambient Air Quality Index (HJ 633-2012)", published by Ministry of Ecology and Environment of the People's Republic of China [27], air quality index is a comprehensive index for air pollution. This index can effectively reflect the impact of various pollutants on air pollution, including PM2.5, $\mathrm{PM} 10, \mathrm{O}_{3}, \mathrm{SO}_{2}, \mathrm{NO}_{2}$ and $\mathrm{CO}$. Air quality index is the maximum air quality subindex of six pollutants, as depicted in Equation 6, and each air quality subindex (IAQI $\boldsymbol{I}_{\boldsymbol{n}}$, equal to $\left.\boldsymbol{I A Q I}_{\boldsymbol{p}}\right)$ is determined by the mass concentration of pollutant $\mathrm{P}\left(\mathrm{PM} 2.5, \mathrm{PM} 10, \mathrm{O}_{3}, \mathrm{SO}_{2}, \mathrm{NO}_{2}\right.$ and $\left.\mathrm{CO}\right)$. Equation 7 calculates air quality subindex of pollutant $\mathrm{P}$ by data interpolation method, where $I A Q I_{p}$ is air quality subindex of pollutant $\mathrm{P} ; C_{p}$ is mass concentration of pollutant $\mathrm{P} ; B P_{H i}$ is the high value of the concentration limit value close to $C_{p} ; B P_{L o}$ is the low value of the concentration limit value close to $C_{p} ; I A Q I_{H i}$ is the individual air quality index of $B P_{H i} ; I A Q I_{L o}$ is the individual air quality index of $B P_{L o}$. The air quality subindex and concentration limit values of pollutants, are shown in Table 2, obtained from the “Technical Regulation on Ambient Air Quality Index (HJ 633-2012)” [27].

$$
\begin{gathered}
A Q I=\max \left\{I A Q I_{1}, I A Q I_{2}, \cdots I A Q I_{n}\right\} \\
I A Q I_{p}=\frac{I A Q I_{H i}-I A Q I_{L o} o}{B P_{H i}-B P_{L o}}\left(C_{p}-B P_{L o}\right)+I A Q I_{L o}
\end{gathered}
$$

Table 2 Air quality subindex and concentration limit values of pollutants [27]

\begin{tabular}{ccccccc}
\hline Air & Sulfur & Nitrogen & \multicolumn{5}{c}{ Carbon } \\
quality & $\begin{array}{c}\text { Dioxide } \\
\text { subindex }\end{array}$ & $\begin{array}{c}\text { Dioxide } \\
\mathrm{SO}_{2}\end{array}$ & $\begin{array}{c}\mathrm{PM} 10 \\
\mathrm{NO}_{2}\end{array}$ & $\begin{array}{c}\text { Monoxide } \\
\left(\mu \mathrm{g} / \mathrm{m}^{3}\right)\end{array}$ & $\begin{array}{c}\text { Ozone } \mathrm{O}_{3} \\
\left(\mu \mathrm{g} / \mathrm{m}^{3}\right)\end{array}$ & $\begin{array}{c}\mathrm{PM} 2.5 \\
\left(\mu \mathrm{g} / \mathrm{m}^{3}\right)\end{array}$ \\
\hline$(\mathrm{IAQI})$ & $\left(\mu \mathrm{g} / \mathrm{m}^{3}\right)$ & $\left(\mu \mathrm{g} / \mathrm{m}^{3}\right)$ & & $\left(\mathrm{mg} / \mathrm{m}^{3}\right)$ & & \\
\hline 0 & 0 & 0 & 0 & 0 & 0 & 0 \\
50 & 150 & 100 & 50 & 5 & 160 & 35 \\
100 & 500 & 200 & 150 & 10 & 200 & 75
\end{tabular}




\begin{tabular}{ccccccc}
150 & 650 & 700 & 250 & 35 & 300 & 115 \\
200 & 800 & 1200 & 350 & 60 & 400 & 150 \\
300 & -- & 2340 & 420 & 90 & 800 & 250 \\
400 & -- & 3090 & 500 & 120 & 1000 & 350 \\
500 & -- & 3840 & 600 & 150 & 1200 & 500 \\
\hline
\end{tabular}

If the mass concentration of pollutant $\mathrm{P}\left(C_{p}\right)$ is given, $C_{p}$ could be inserted in the interval from the lowvalue of the concentration limit value $\left(B P_{L o}\right)$ to the high-value of the concentration limit value $\left(B P_{H i}\right)$.

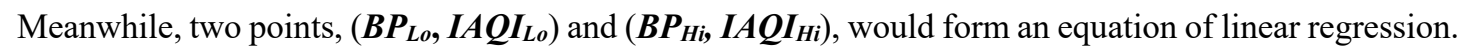
Then, air quality subindex of pollutant $\mathrm{P}(\boldsymbol{I} A \boldsymbol{Q} \boldsymbol{I})$ could be determined by linear regression.

When $\mathrm{AQI} \leq 50$, air quality is optimal. When $50<\mathrm{AQI} \leq 100$, air quality is good. When $100<$ $\mathrm{AQI} \leq 150$, it is slight pollution. When $150<\mathrm{AQI} \leq 200$, it is moderate pollution. When $200<\mathrm{AQI} \leq 300$, it is heavy pollution. When AQI $>300$, it is serious pollution. Higher AQI indicates more serious air pollution and higher concentration of particulate matters in air [19].

\subsection{Studied sites}

To investigate the attenuation effect of air pollution on regional solar radiation, five regions with heavy air pollution, namely, Beijing, Tianjin, Jinan, Xi'an and Zhengzhou, are selected as studied sites, as marked with black triangles in Figure 1. The mean annual AQI of each region is greater than 100 for slight air pollution, where the polluted days of Beijing exceeds 170 days in 2016, with $47.4 \%$ of whole year. Thus, Beijing is employed as case study in Section 3.1, to discuss the attenuation of solar radiation by air pollutants with the method present in Section 2.1, including the attenuation models composed of clearness index and AQI, and monthly solar radiation attenuation calculated by attenuation models of Beijing. Then, other four studied sites are proposed to get more attenuation models in Section 3.2, and further obtain the clearness index attenuation and solar radiation attenuation from monthly scale and annual scale. Meanwhile, the difference of attenuation effect among five regions is also discussed.

\subsection{Data}

The historical data collected from the five studied sites from 2014 to 2016 is used in this study, including solar radiation, sunshine duration, historical weather, longitude, latitude, and air quality index, collected from the National Meteorological Information Center [28] and the Ministry of Ecology and Environment of the People's Republic of China [29]. Detailed information about five weather stations is depicted in 


\begin{tabular}{|c|c|c|c|c|c|c|}
\hline Regions & $\begin{array}{l}\text { Latitude } \\
\qquad(\mathrm{N})\end{array}$ & $\begin{array}{c}\text { Longitude } \\
\text { (E) }\end{array}$ & $\begin{array}{l}\text { Altitude } \\
\text { (m) }\end{array}$ & $\begin{array}{c}\mathrm{H} \\
\left(\mathrm{MJ} /\left(\mathrm{m}^{2} \cdot \mathrm{d}\right)\right)\end{array}$ & AQI & $\begin{array}{l}\text { Sunshine } \\
\text { duration (h) }\end{array}$ \\
\hline Beijing & $39^{\circ} 48^{\prime}$ & $116^{\circ} 28^{\prime}$ & 31.3 & 14.79 & 120 & 6.66 \\
\hline Tianjin & $39^{\circ} 05^{\prime}$ & $117^{\circ} 03^{\prime}$ & 3.5 & 14.45 & 109 & 6.22 \\
\hline Jinan & $36^{\circ} 36^{\prime}$ & $117^{\circ} 00^{\prime}$ & 170.3 & 12.95 & 125 & 6.06 \\
\hline Xi'an & $34^{\circ} 26^{\prime}$ & $108^{\circ} 58^{\prime}$ & 410 & 14.64 & 108 & 8.35 \\
\hline Zhengzhou & $34^{\circ} 43^{\prime}$ & $113^{\circ} 39^{\prime}$ & 110.4 & 13.03 & 127 & 5.05 \\
\hline
\end{tabular}

Table 3, where $\boldsymbol{H}$ is annual average daily global solar radiation (in $\mathrm{MJ} /\left(\mathrm{m}^{2} \cdot \mathrm{d}\right)$ ).

Table 3 Geographic information and annual average daily meteorological data collected from five studied sites from 2014 to 2016

\section{Results and Discussions}

\subsection{Attenuation of solar radiation by air pollutants in Beijing}

According to the evaluation method described in Section 2.1, the variation of clearness index with AQI under different weather levels is summarized in Section 3.1, using data collected from Beijing. Beijing, the capital of China, is a political and economic center of the world, and has huge solar energy resources, but with heavy air pollution, which is a typical city of China for current research. If Beijing can be selected as a typical region, the significance of air pollution on solar energy application would capture a lot of attention.

\subsubsection{Attenuation of solar radiation under different weather levels}

As shown in Figure 2, with weather level increases, the sky was shifting from fully sunny to fully overcast. Due to the increasing amount of clouds in the sky, the sunlight became more scattered, resulting in a gradual decrease of clearness index. Meanwhile, the gradient of clearness index with increased AQI gradually decreased and the data gradually scattered, where root mean square error (RMSE) increased from 0.0678 to 0.0955 and the mean absolute percentage error (MAPE) also increased from $8.21 \%$ to $57.51 \%$ (in Table 4). 


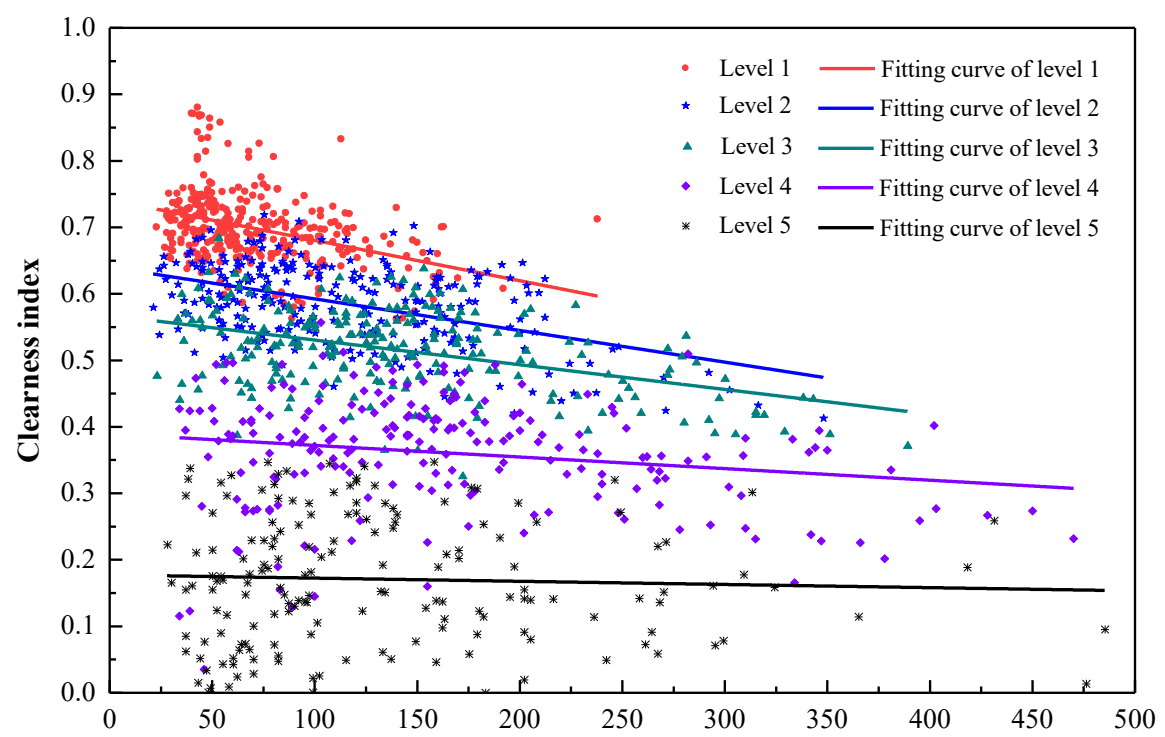

Figure 2 The variation of clearness index with AQI under different weather levels in Beijing

Table 4 depicts fitting results of linear function of five weather levels, where " $a$ " is slope and "b" is intercept. Clearness index decreased but with diverse gradients of five weather levels as AQI increased. When weather level was 1 , there was little or no cloud covering sky, and the attenuation effect of air pollution on solar radiation was most obvious, with a higher attenuation coefficient $|\boldsymbol{a}|$ (absolute value of $a$ ) of $6.08 \times 10^{-4}$. When weather levels increased, the amount and thickness of clouds in sky increased gradually, resulting in decreased solar radiation received on the ground ( $b$ value decreased continuously). Meanwhile, based on the hierarchical classification of weather conditions, the diversity of weather changes and the uncertainty of duration lead to more scattered data. The weather representation was more complicated, and it was more difficult to classify data, with wider data distribution range for cloudy days.

In real polluted air, PM2.5 and PM10 mainly attenuate part near-infrared energy, but slightly absorb part visible light $[25,26]$. Due to the absorption of water in the clouds, solar radiation, after passing through clouds but before fog-haze, contains a large part of visible light and a small proportion of infrared energy $[30,31]$. At the same time, the attenuation of particulate matters on solar radiation is mainly reflected on the infrared part, but this part of energy has little impact on the overall solar energy (compared with the visible part) [16,32], resulting in smaller attenuation of air pollution on overall solar radiation in cloudy days. Directional absorption of infrared part by cloud is the main reason of reducing attenuation rate. In addition, data in cloudy days are scattered, which has a direct impact on data fitting. This may be one reason for the low attenuation rate of cloudy days. 
Table 4 Solar radiation attenuation models under different weather levels in Beijing

\begin{tabular}{ccccccc}
\hline Weather Levels & \multicolumn{2}{c}{ Coefficient } & Sample & Correlation \\
& $\mathrm{a}$ & $\mathrm{b}$ & RMSE & MAPE \\
coefficients & & & \\
\hline Level 1 & $-6.08 \times 10^{-4}$ & 0.7413 & 325 & 0.374 & 0.0678 & $8.21 \%$ \\
Level 2 & $-4.756 \times 10^{-4}$ & 0.6399 & 264 & 0.475 & 0.0761 & $10.95 \%$ \\
Level 3 & $-3.7132 \times 10^{-4}$ & 0.5671 & 232 & 0.428 & 0.0758 & $12.82 \%$ \\
Level 4 & $-1.744 \times 10^{-4}$ & 0.3895 & 220 & 0.187 & 0.0902 & $28.66 \%$ \\
Level 5 & $-4.784 \times 10^{-5}$ & 0.1773 & 169 & 0.045 & 0.0955 & $57.51 \%$ \\
\hline
\end{tabular}

\subsubsection{Attenuation of solar radiation in different months}

Based on the above solar radiation attenuation models, the attenuation effect of air pollution on solar radiation is investigated in different seasons in Beijing. As shown in Figure 3, the weather conditions of each month of the year are classified according to the evaluation method proposed in Section 2.1. The total days of Level 1 and Level 2 is smaller in February, June, July and August, and mainly with cloudy or thunderstorm days.

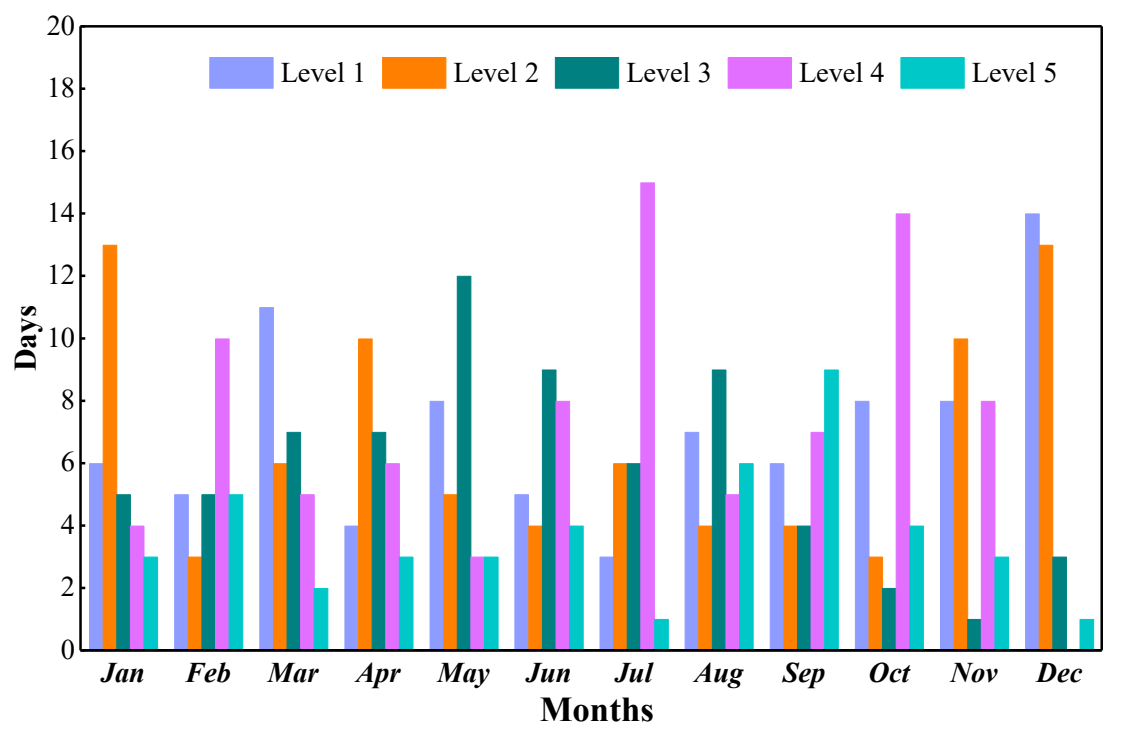

Figure 3 Classification of weather levels of Beijing in 2014

Figure 4 exhibits the temporal distribution of air pollution in Beijing in 2014. The duration of air pollution varied greatly every month, and the pollution days in almost every month were more than 15 days. At the same time, the pollution days in February, July and August were more, but heavy pollution and serious pollution occurred frequently in October, November, January, February and March, mainly due to the emission of particulate matters from large-scale centralized heating in Beijing. Figure 5 reveals the distribution of air pollution corresponding to each weather level. Only the proportion of pollution days 
of Level 1 was small, due to less water vapor in the air and higher air temperature. More water vapor in the air would aggravate the agglomeration of aerosol and come into being PM2.5 and PM10, resulting in increased pollution days. Meanwhile, higher air temperature in winter would decrease heating load of buildings, and emission of central heating would decrease, which is a positive factor to optimize air pollution. The increased clouds will increase the days of pollution to a certain extent. However, there is no clear linear relationship between air pollution and weather levels, and the correlation is related to the local climate.

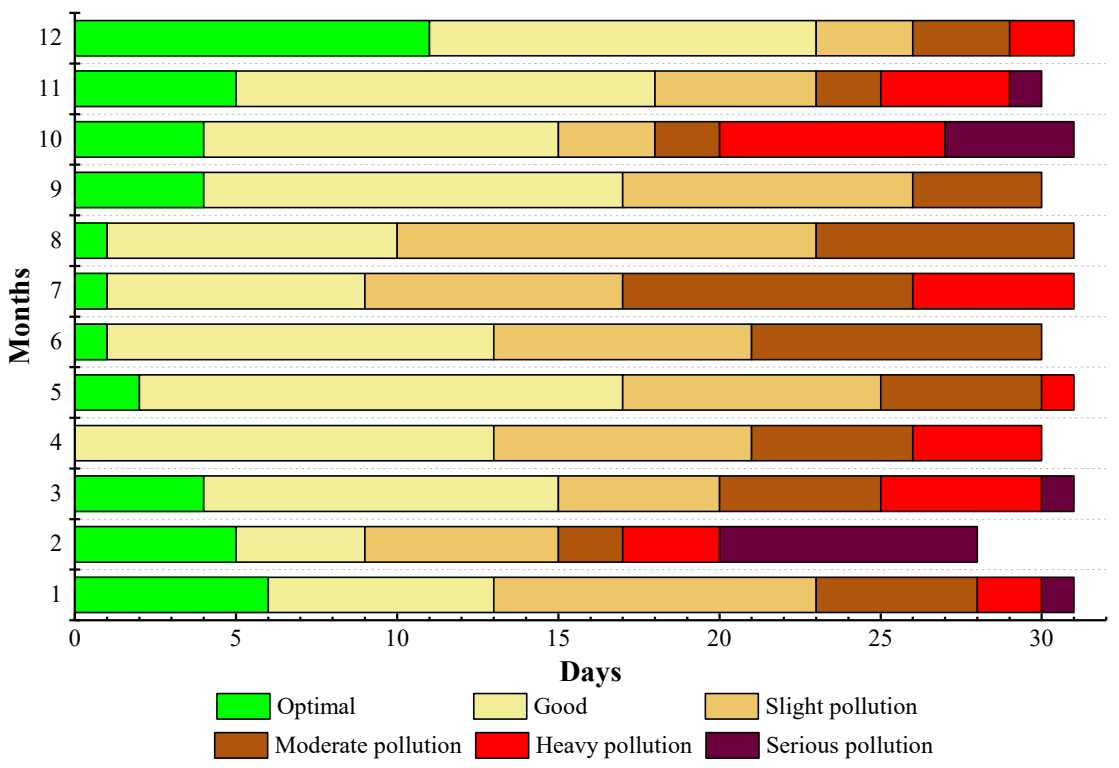

Figure 4 the temporal distribution of air pollution of Beijing in 2014
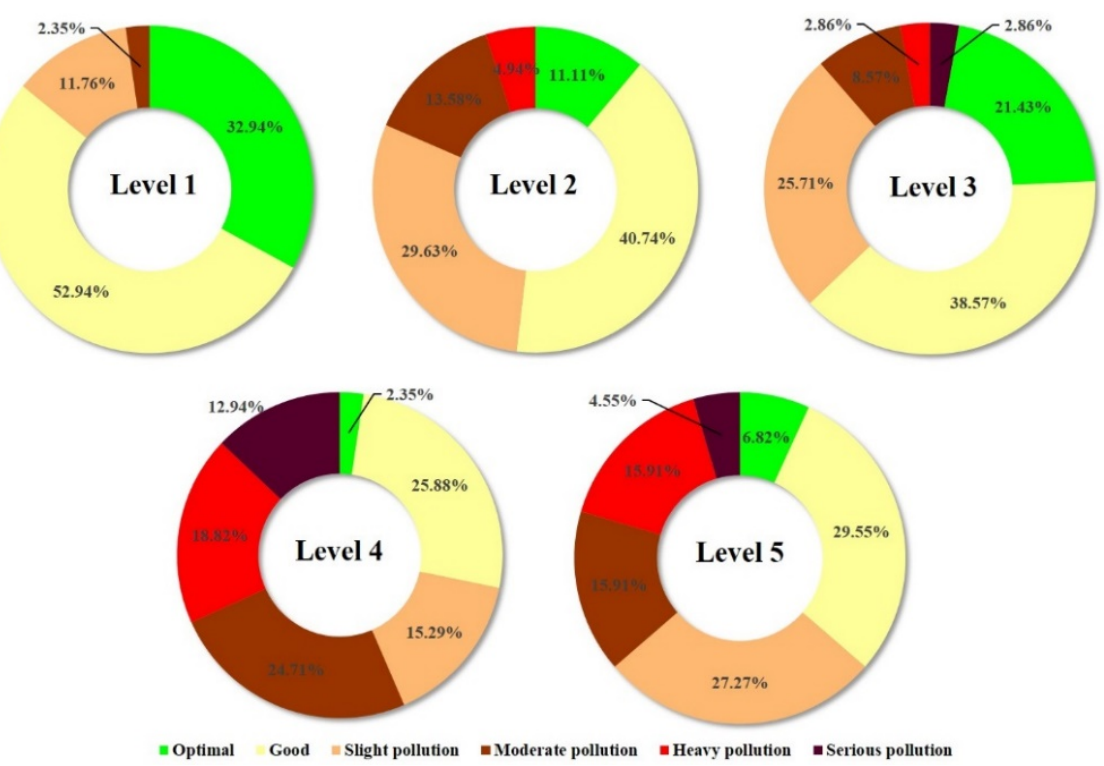

Figure 5 The distribution of air pollution corresponding to each weather level of Beijing in 2014

After getting the correlation between clearness index and air quality index, it needs to further evaluate 
the detailed attenuation effect of air pollution on regional solar radiation. In this study, two variables were defined, namely, clearness index attenuation and solar radiation attenuation. Clearness index attenuation, also called solar radiation attenuation ratio, is the ratio of solar radiation attenuation to extraterrestrial horizontal daily global solar radiation, while solar radiation attenuation is the amount of solar radiation attenuation caused by air pollution.

According to the "Technical Regulation on Ambient Air Quality Index (HJ 633-2012)" issued by the Ministry of Ecology and Environment of the People's Republic of China, air is polluted when AQI is greater than 100. Therefore, this threshold is selected to decide whether air is polluted. Daily/monthly clearness index attenuation and monthly solar radiation attenuation are calculated by Equations 8-10,

$$
K_{d}=|a| \cdot(A Q I-100)
$$

$$
K_{m}=\sum_{1}^{n} K_{d}
$$

$$
\boldsymbol{G}_{m}=\sum_{1}^{n} \boldsymbol{G}_{0} \cdot \boldsymbol{K}_{\boldsymbol{d}}
$$

where $\boldsymbol{K}_{\boldsymbol{d}}$ and $\boldsymbol{K}_{\boldsymbol{m}}$ is daily and monthly clearness index attenuation (or solar radiation attenuation ratio, dimensionless), $\boldsymbol{G}_{\boldsymbol{m}}$ is monthly solar radiation attenuation $\left(\mathrm{MJ} / \mathrm{m}^{2}\right), \boldsymbol{G}_{\mathbf{0}}$ is extraterrestrial horizontal daily global solar radiation $\left(\mathrm{MJ} / \mathrm{m}^{2}\right)$, and $\boldsymbol{n}$ is total days of a month. In addition, $|\boldsymbol{a}|$ is the absolute value of slope of linear function (called attenuation coefficient).

As shown in Figure 6, the clearness index attenuation was high from March to August but low from September to February. In September, the clearness index attenuation reached its lowest value of $2.6 \%$ for $2014,2.7 \%$ for 2015 and $2.8 \%$ for 2016 , respectively, mainly due to less days of slight pollution and moderate pollution. In addition, level 4 and level 5 with lower attenuation coefficient in September were also reasons for the low clearness index attenuation. Meanwhile, solar radiation attenuation showed obvious seasonal variation. The maximum solar radiation attenuation was $53.51 \mathrm{MJ} / \mathrm{m}^{2}$ in July for 2014 , $52.25 \mathrm{MJ} / \mathrm{m}^{2}$ in May for 2015 and $60.42 \mathrm{MJ} / \mathrm{m}^{2}$ in May for 2016, while the minimum value was 16.89 $\mathrm{MJ} / \mathrm{m}^{2}$ in December for 2014, $12.42 \mathrm{MJ} / \mathrm{m}^{2}$ in November for 2015 and $19.27 \mathrm{MJ} / \mathrm{m}^{2}$ in January for 2016. The monthly solar radiation attenuation is the product of the extraterrestrial solar radiation and clearness index attenuation. Since clearness index changes slightly through the year, monthly solar radiation attenuation is mainly determined by the extraterrestrial solar radiation, that is, solar altitude angle. 


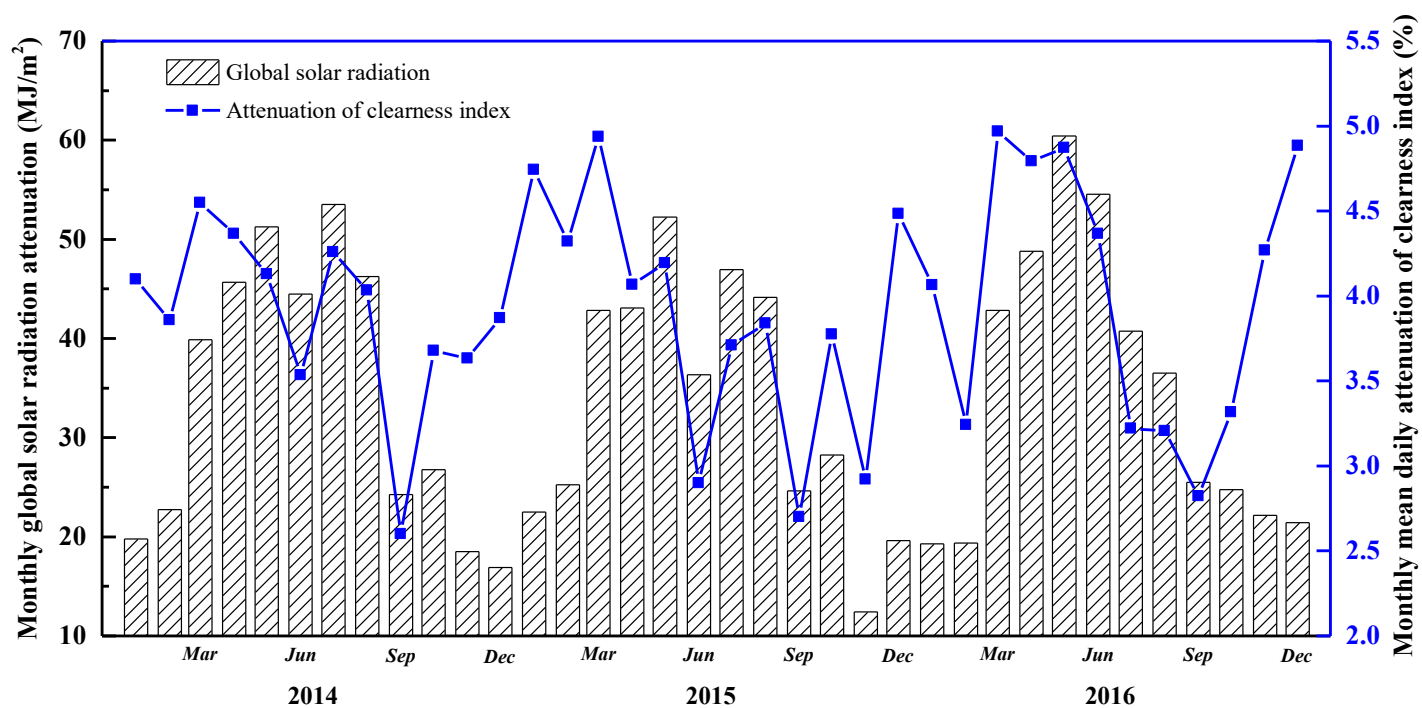

Figure 6 Monthly solar radiation attenuation and monthly mean daily attenuation of clearness index of

$$
\text { Beijing in 2014, } 2015 \text { and } 2016
$$

From the view of annual solar radiation, solar radiation attenuation in 2014, 2015 and 2016 were 410.02 $\mathrm{MJ} / \mathrm{m}^{2}, 403.87 \mathrm{MJ} / \mathrm{m}^{2}$ and $416.35 \mathrm{MJ} / \mathrm{m}^{2}$, respectively. In 2015 , the number of polluted days decreased by 13 days compared with 2014, with more slight pollution, resulting in a $1.5 \%$ reduction in solar radiation attenuation throughout the year. The polluted days in 2016 was less than that in 2014 by 19 days, but the total number of days in weather level 1, level 2 and level 3, was more than that in 2016 by 26 days, which was the main reason why Beijing in 2016 had a larger attenuation. In addition, although the days of air pollution decreased due to the environmental control of Beijing government, the pollutants in the air were even smaller and the original PM2.5 was converted to PM1. According to observations [17], the mass concentrations of PM1 in the air of both autumn and winter in 2016 in Beijing were between $59.16-57.05 \mu \mathrm{g} / \mathrm{m}^{3}$. Because of the higher specific surface area of PM1, the extinction effect of PM1 on solar radiation is more significant, even with improved air pollution conditions.

\subsection{Regional variations of solar radiation attenuation}

\subsubsection{Evaluation of monthly solar radiation attenuation}

Figure 7 shows the monthly variation of average daily clearness index attenuation in Tianjin, Xi'an, Zhengzhou and Jinan. The attenuation of clearness index in Tianjin, Xi'an and Zhengzhou fluctuated greatly throughout the year, with significantly increased values from October to March. In these months, large-scale centralized heating in northern China resulted in higher emissions from thermal power plants, leading to higher pollutant concentrations and increased air pollution [33, 34]. As the capital city, Beijing 
was the first city to propose that coal-fired boilers should be replaced by gas-fired boilers, which weakened this increased pollution trend to a certain extent. At the same time, the lower attenuation rate in February may be related to the shutdown or reduction of factories, mainly due to the large number of workers returning home during the period of the traditional Spring Festival in China. However, the clearness index attenuation in Jinan varied slightly in the whole year, and the monthly mean clearness index attenuation was only $2.69 \%$. The difference of clearness index attenuation among Tianjin, Xi'an and Zhengzhou was mainly attributed to the higher attenuation coefficient (absolute value of $\boldsymbol{a}$ in Table 5), and the attenuation coefficient was related to the air pollutants and mass concentration of particulate matters in the local air. When the concentration of particulate matters was the same, the smaller the particle size, the more significant the extinction of sunlight $[35,36]$. In addition, the regional monsoon climate accelerated the migration and accumulation of particulate matters in the air, resulting in the same fluctuations of clearness index in September and October in the four cities.

Figure 8 exhibits the monthly variation of global solar radiation attenuation in four cities. The amount of solar radiation attenuation in each city was high from March to August, and small from September to February, and cyclically changing with the seasons. Solar radiation attenuation is the product of clearness index attenuation and extraterrestrial horizontal global solar radiation. Due to greater solar altitude in summer, extraterrestrial horizontal global solar radiation is higher than that in winter, and played a dominant role in the calculation of solar radiation attenuation, resulting in larger solar radiation attenuation in summer and smaller in winter. For Xi' an and Zhengzhou with same latitude, solar radiation attenuation in Xi'an was more significant, with a monthly average value of $19.36 \%$ higher than Zhengzhou. The reference [37] has indicated that the average daily mass concentration of PM10 in Xi'an was $216 \mu \mathrm{g} / \mathrm{m}^{3}$, while that of Zhengzhou was $181 \mu \mathrm{g} / \mathrm{m}^{3}$, during the central heating period (November and December) in 2016. For Jinan, the low solar radiation attenuation coefficient determined that the radiation attenuation in this area was small, with the monthly average attenuation of only $23.72 \mathrm{MJ} / \mathrm{m}^{2}$. Even though Tianjin has a higher latitude, its attenuation was as high as $54.26 \mathrm{MJ} / \mathrm{m}^{2}$, which was directly related to the mass concentration of ultrafine particles in the air [38]. 
Table 5 Solar radiation attenuation models under different weather levels in four cities

\begin{tabular}{cccccccc}
\hline \multirow{2}{*}{ Cities } & Weather & \multicolumn{2}{c}{ Coefficient } & $\begin{array}{c}\text { Sample } \\
\text { size }\end{array}$ & $\begin{array}{c}\text { Correlation } \\
\text { coefficients }\end{array}$ & \multirow{2}{*}{ RMSE } & MAPE \\
& Levels & $\mathrm{a}$ & $\mathrm{b}$ & & & \\
\hline \multirow{2}{*}{ Tianjin } & Level 1 & $-1.1 \times 10^{-3}$ & 0.783 & 202 & 0.373 & 0.0880 & $9.44 \%$ \\
& Level 2 & $-7.381 \times 10^{-4}$ & 0.698 & 325 & 0.382 & 0.0873 & $11.05 \%$ \\
& Level 3 & $-4.806 \times 10^{-4}$ & 0.592 & 197 & 0.274 & 0.1005 & $16.29 \%$ \\
& Level 4 & $-4.839 \times 10^{-4}$ & 0.443 & 217 & 0.345 & 0.1069 & $34.75 \%$ \\
& Level 5 & $-1.362 \times 10^{-4}$ & 0.216 & 154 & 0.071 & 0.1018 & $76.50 \%$ \\
Jinan & Level 1 & $-2.127 \times 10^{-4}$ & 0.644 & 221 & 0.184 & 0.0508 & $6.65 \%$ \\
& Level 2 & $-3.022 \times 10^{-4}$ & 0.581 & 323 & 0.235 & 0.0595 & $8.98 \%$ \\
& Level 3 & $-3.494 \times 10^{-4}$ & 0.503 & 172 & 0.235 & 0.0711 & $13.54 \%$ \\
& Level 4 & $-1.079 \times 10^{-4}$ & 0.341 & 183 & 0.089 & 0.0943 & $36.46 \%$ \\
& Level 5 & $-3.832 \times 10^{-5}$ & 0.181 & 196 & 0.021 & 0.0928 & $73.23 \%$ \\
& Xevel 1 & $-5.5 \times 10^{-4}$ & 0.747 & 163 & 0.286 & 0.0755 & $9.30 \%$ \\
& Level 2 & $-5.916 \times 10^{-4}$ & 0.684 & 308 & 0.387 & 0.0820 & $10.70 \%$ \\
& Level 3 & $-5.597 \times 10^{-4}$ & 0.605 & 182 & 0.359 & 0.0912 & $13.53 \%$ \\
& Level 4 & $-4.795 \times 10^{-4}$ & 0.404 & 191 & 0.382 & 0.0721 & $19.00 \%$ \\
& Level 5 & $-5.891 \times 10^{-5}$ & 0.196 & 247 & 0.039 & 0.1221 & $37.94 \%$ \\
& Level 1 & $-5.758 \times 10^{-4}$ & 0.711 & 138 & 0.420 & 0.0382 & $4.63 \%$ \\
& Level 2 & $-5.172 \times 10^{-4}$ & 0.637 & 264 & 0.459 & 0.0475 & $7.00 \%$ \\
& Level 3 & $-3.292 \times 10^{-4}$ & 0.532 & 194 & 0.307 & 0.0587 & $10.00 \%$ \\
& Level 4 & $-2.466 \times 10^{-4}$ & 0.392 & 299 & 0.255 & 0.0988 & $21.82 \%$ \\
& Level 5 & $-9.527 \times 10^{-6}$ & 0.126 & 200 & 0.01 & 0.0717 & $39.77 \%$ \\
\hline
\end{tabular}




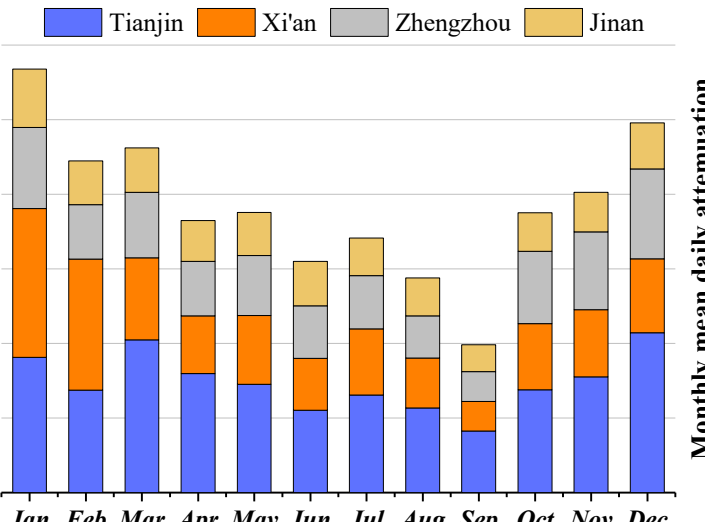

Jan Feb Mar Apr May Jun Jul Aug Sep Oct Nov Dec

Months / 2014

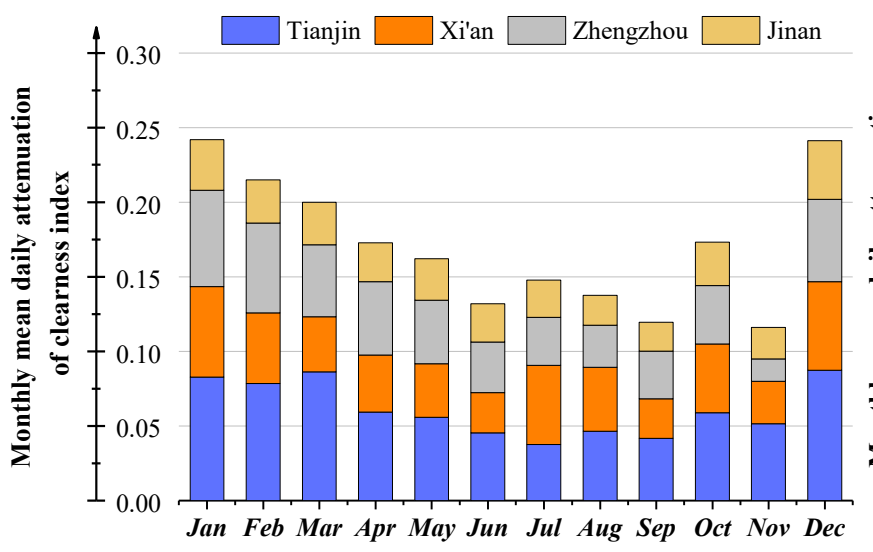

Months / 2015

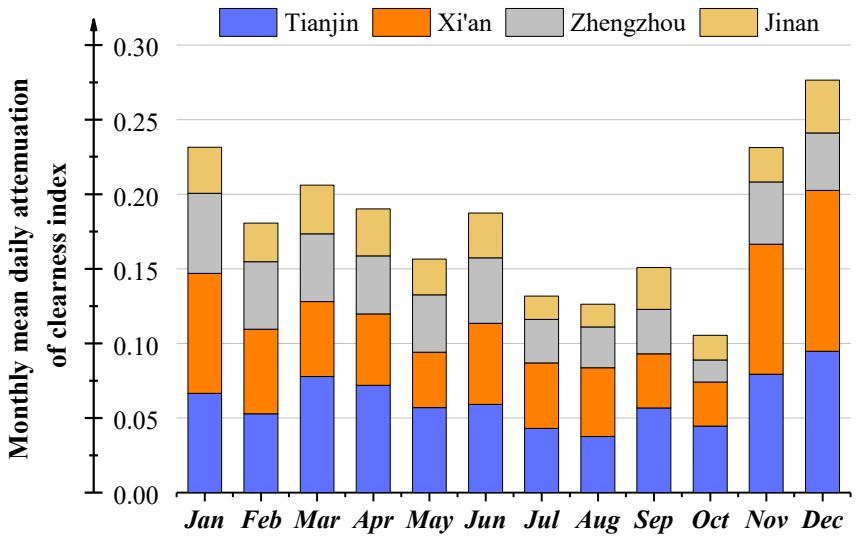

Months / 2016

Figure 7 Monthly mean daily attenuation of clearness index VS Months of four cities

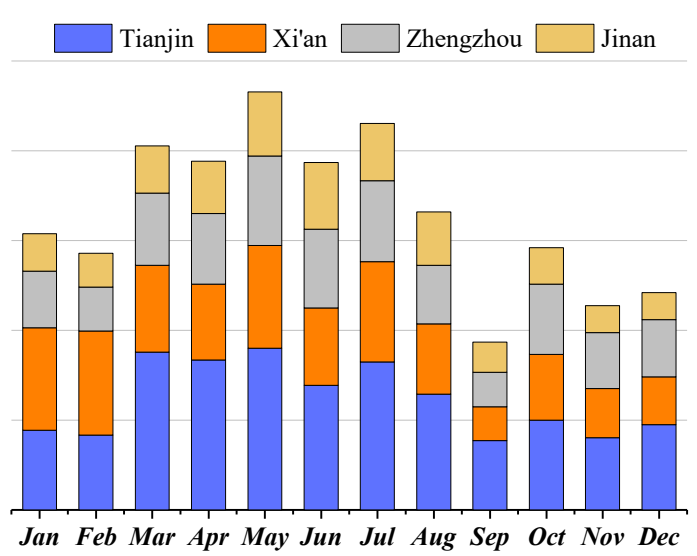

Months / 2014

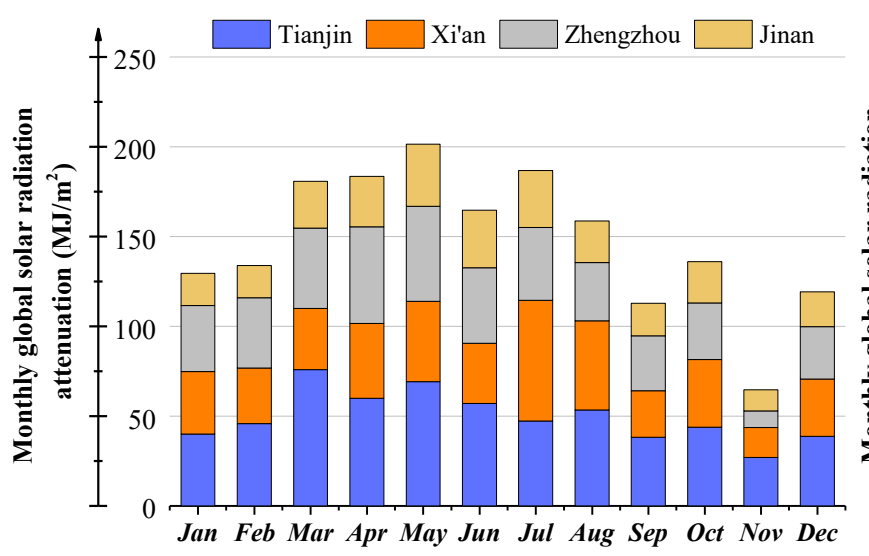

Months / 2015

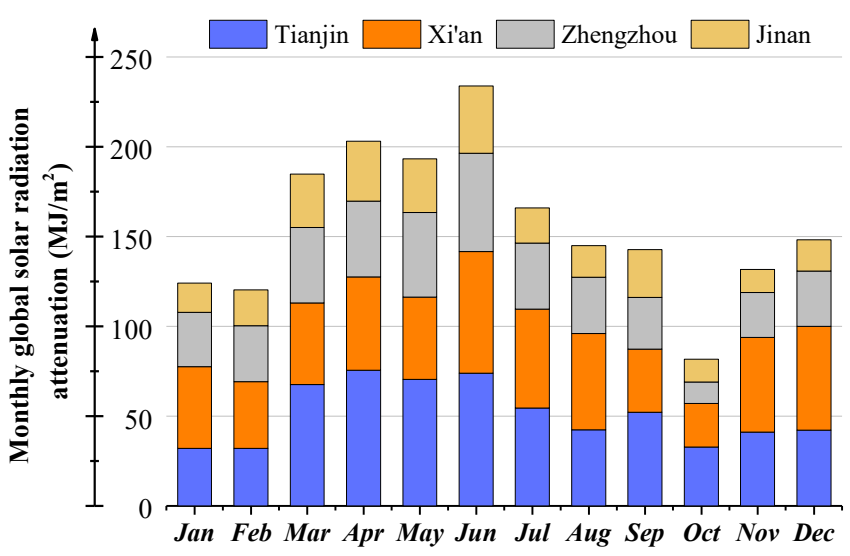

Months / 2016

Figure 8 Monthly global solar radiation attenuation VS Months of four cities 


\subsubsection{Variations of annual solar radiation attenuation}

From the annual attenuation effect, the changes in both clearness index attenuation and solar radiation attenuation were consistent. For the same city, the property of air pollutants is almost stable. Thus, the higher concentration of pollutants (higher AQI) meant greater solar radiation attenuation, which is easy to obtain from Figure 9. However, for different cities, higher AQI did not necessarily lead to greater solar radiation attenuation. For example, although there was a higher AQI for Zhengzhou, the solar radiation attenuation of Zhengzhou was not the maximum value. According to Equations 8 to 10 , the attenuation of solar radiation depends on three factors, namely, attenuation coefficient, number of days with different weather levels and air quality index (AQI), where attenuation coefficient plays the decisive role. The highest attenuation coefficient of each weather level in four regions is Tianjin, and this maybe the crucial factor for greatest annual solar radiation attenuation. Besides, more days of level 1 and level 2 with higher attenuation coefficient for Tianjin, would be another key factor for greater solar radiation attenuation. Thus, the calculated solar radiation attenuation in Tianjin was greater than that in Zhengzhou, even though the AQI of Zhengzhou was higher. In general, annual mean solar radiation attenuation ratio of Tianjin was the highest of $6.56 \%\left(651.17 \mathrm{MJ} / \mathrm{m}^{2}\right)$, followed by Xi' an $\left(4.94 \%, 510.42 \mathrm{MJ} / \mathrm{m}^{2}\right)$, Zhengzhou $\left(3.99 \%, 427.64 \mathrm{MJ} / \mathrm{m}^{2}\right)$ and Jinan $\left(2.69 \%, 284.66 \mathrm{MJ} / \mathrm{m}^{2}\right)$.

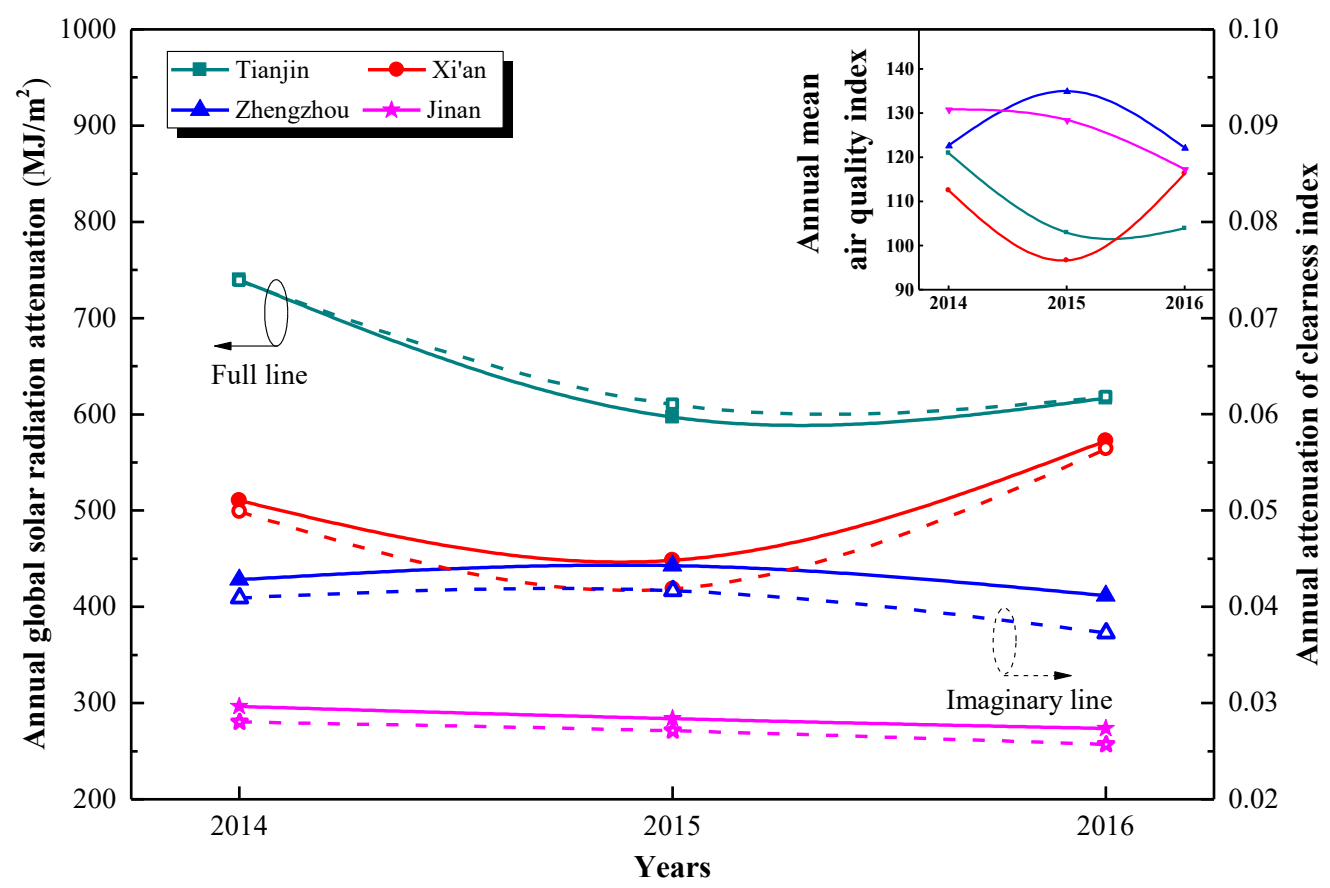

Figure 9 The annual solar radiation attenuation and annual clearness index attenuation of four cities 


\section{Conclusions}

Increased air pollution would weaken the transmission of solar radiation, and reduce the performance of solar energy systems. To evaluate the attenuation effect of air pollution on solar radiation, historical data of five regions from 2014 to 2016, is used to discuss the correlation between solar radiation and air pollution, and evaluate solar radiation attenuation caused by air pollution. The following conclusions are obtained.

(1) The daily clearness index decreases with increased air quality index, and attenuation coefficient of these attenuation models reduces as weather levels ranging from level 1 to level 5, with the maximum attenuation coefficient for each weather level of Tianjin. The type of air pollutants, mass concentration and size of particulate matter are crucial factors for attenuation coefficient.

(2) Monthly clearness index attenuation of five regions is high from October to March and low from April to September, but monthly solar radiation attenuation is great from March to August due to greater extraterrestrial horizontal daily global solar radiation.

(3) In five studied sites, annual solar radiation attenuation in Tianjin and Xi'an are larger, the value being $651.17 \mathrm{MJ} / \mathrm{m}^{2}$ and $510.42 \mathrm{MJ} / \mathrm{m}^{2}$, while that in Beijing, Zhengzhou and Jinan is smaller with 410.08 $\mathrm{MJ} / \mathrm{m}^{2}, 427.64 \mathrm{MJ} / \mathrm{m}^{2}$, and $284.66 \mathrm{MJ} / \mathrm{m}^{2}$, respectively. At the same time, solar radiation attenuation ratios of Tianjin, Beijing, Xi'an, Zhengzhou and Jinan, are 6.56\%, 3.92\%, 4.94\%, 3.99\% and 2.69\%.

\section{Acknowledgement}

The authors gratefully acknowledge the funding support from the National Key R\&D Program of China (No. 2017YFC0702900). The authors thank warmly the National Meteorological Information Center issued by China Meteorological Administration (http://data.cma.cn/site/index.html) for their data support.

\section{References}

[1] Chunxiao Zhang, Chao Shen, Shen Wei, Yuan Wang, Guoquan Lv, Cheng Sun, A review on recent development of cooling technologies for photovoltaic modules, Journal of thermal science (2020) DOI: https://doi.org/10.1007/s11630-020-1350-y.

[2] W. Wei, L. Ni, W. Wang, Y. Yao, Experimental and theoretical investigation on defrosting characteristics of a multi-split air source heat pump with vapor injection, Energy and Buildings 217 (2020) 109938.

[3] W. Wei, L. Ni, L. Xu, Y. Yang, Y. Yao, Application characteristics of variable refrigerant flow heat pump system with vapor injection in severe cold region, Energy and Buildings 211 (2020) 109798.

[4] C. Shen, G. Lv, S. Wei, C. Zhang, C. Ruan, Investigating the performance of a novel solar 
lighting/heating system using spectrum-sensitive nanofluids, Applied Energy 270 (2020) 115208.

[5] M. Aklin, P. Bayer, S.P. Harish, J. Urpelainen, Does basic energy access generate socioeconomic benefits? A field experiment with off-grid solar power in India, Science Advances 3(5) (2017) e1602153. [6] A. Zervos, Renewables 2018 - Global Status Report, Renewable Energy Policy Network for the 21st Century, 2018.

[7] J. Day, S. Senthilarasu, T.K. Mallick, Improving spectral modification for applications in solar cells: A review, Renewable Energy 132 (2019) 186-205.

[8] S.-Y. Wu, C. Chen, L. Xiao, Heat transfer characteristics and performance evaluation of water-cooled PV/T system with cooling channel above PV panel, Renewable Energy 125 (2018) 936-946.

[9] S. Preet, B. Bhushan, T. Mahajan, Experimental investigation of water based photovoltaic/thermal (PV/T) system with and without phase change material (PCM), Solar Energy 155 (2017) 1104-1120.

[10] A.A. Kazem, M.T. Chaichan, H.A. Kazem, Dust effect on photovoltaic utilization in Iraq: Review article, Renewable and Sustainable Energy Reviews 37 (2014) 734-749.

[11] O.K. Ahmed, K.I. Hamada, A.M. Salih, Enhancement of the performance of Photovoltaic/Trombe wall system using the porous medium: Experimental and theoretical study, Energy 171 (2019) 14-26.

[12] Z. Wang, Y. Li, K. Wang, Z. Huang, Environment-adjusted operational performance evaluation of solar photovoltaic power plants: A three stage efficiency analysis, Renewable and Sustainable Energy Reviews 76 (2017) 1153-1162.

[13] S. Soltani, A. Kasaeian, H. Sarrafha, D. Wen, An experimental investigation of a hybrid photovoltaic/thermoelectric system with nanofluid application, Solar Energy 155 (2017) 1033-1043.

[14] M.M. Rahman, M. Hasanuzzaman, N.A. Rahim, Effects of operational conditions on the energy efficiency of photovoltaic modules operating in Malaysia, Journal of Cleaner Production 143 (2017) 912924.

[15] S.A. Khalil, A.M. Shaffie, Attenuation of the solar energy by aerosol particles: A review and case study, Renewable and Sustainable Energy Reviews 54 (2016) 363-375.

[16] Z. Cheng, S. Wang, J. Jiang, Q. Fu, C. Chen, B. Xu, J. Yu, X. Fu, J. Hao, Long-term trend of haze pollution and impact of particulate matter in the Yangtze River Delta, China, Environmental Pollution 182 (2013) 101-110.

[17] Hanyu Zhang, Shuiyuan Cheng, Sen Yao, Xiaoqi Wang, J. Zhang, Pollution Characteristics and Regional Transport of Atmospheric Particulate Matter in Beijing from October to November, 2016 (In chinese), Environmental Science 40(5) (2019) 1999-2009.

[18] Q. Zhao, W. Yao, C. Zhang, X. Wang, Y. Wang, Study on the influence of fog and haze on solar radiation based on scattering-weakening effect, Renewable Energy 134 (2019) 178-185.

[19] W. Yao, C. Zhang, X. Wang, J. Sheng, Y. Zhu, S. Zhang, The research of new daily diffuse solar radiation models modified by air quality index (AQI) in the region with heavy fog and haze, Energy Conversion and Management 139 (2017) 140-150.

[20] J. Liu, W. Fang, X. Zhang, C. Yang, An Improved Photovoltaic Power Forecasting Model With the Assistance of Aerosol Index Data, IEEE Transactions on Sustainable Energy 6(2) (2015) 434-442.

[21] Y. Wang, Y. Yang, N. Zhao, C. Liu, Q. Wang, The magnitude of the effect of air pollution on sunshine hours in China, Journal of Geophysical Research: Atmospheres 117(D21) (2012) n/a-n/a.

[22] N. Zhao, X. Zeng, S. Han, Solar radiation estimation using sunshine hour and air pollution index in China, Energy Conversion and Management 76 (2013) 846-851.

[23] J. Fan, L. Wu, F. Zhang, H. Cai, X. Wang, X. Lu, Y. Xiang, Evaluating the effect of air pollution on global and diffuse solar radiation prediction using support vector machine modeling based on sunshine 
duration and air temperature, Renewable and Sustainable Energy Reviews 94 (2018) 732-747.

[24] C.A.o. Sciences, Report on remote sensing monitoring of China sustainable development 2016, 2017.

[25] J.A. Duffie, W.A. Beckman, Solar Engineering of Thermal Processes, Fourth Edition, 2013.

[26] J.A. Duffie, Solar Engineering of Thermal Processes (Fourth Edition : Design of Photovoltaic Systems, Wiley2013.

[27] M.o.E.a.E.o.t.P.s.R.o. China, Technical Regulation on Ambient Air Quality Index (HJ 633-2012), 2012.

[28] C.M. Administration, National Meteorological Informantion Center (http://data.cma.cn/site/index.html), 2019.

[29] M.o.E.a.E.o.t.P.s.R.o. China, Datacenter (http://datacenter.mee.gov.cn/websjzx/queryIndex.vm), 2019.

[30] L.L. Guo, H. Zheng, Y.L. Lyu, L.Y. Liu, F. Kong, S.R. Wang, Trends in atmospheric particles and their light extinction performance between 1980 and 2015 in Beijing, China, Chemosphere 205 (2018) 52-61.

[31] X. Han, X. Chen, Q. Wang, S.M. Alelyani, J. Qu, Investigation of CoSO4-based Ag nanofluids as spectral beam splitters for hybrid PV/T applications, Solar Energy 177 (2019) 387-394.

[32] J. Petržala, M. Kocifaj, Research on spectral factors towards determining nocturnal ground irradiance under overcast sky conditions in densely populated regions, Journal of Quantitative Spectroscopy and Radiative Transfer 189 (2017) 126-132.

[33] H. Wang, S.-C. Tan, Y. Wang, C. Jiang, G.-y. Shi, M.-X. Zhang, H.-Z. Che, A multisource observation study of the severe prolonged regional haze episode over eastern China in January 2013, Atmospheric Environment 89 (2014) 807-815.

[34] J. Hu, Q. Ying, Y. Wang, H. Zhang, Characterizing multi-pollutant air pollution in China: Comparison of three air quality indices, Environment International 84 (2015) 17-25.

[35] J.A. Ruiz-Arias, C.A. Gueymard, F.J. Santos-Alamillos, S. Quesada-Ruiz, D. Pozo-Vázquez, Bias induced by the AOD representation time scale in long-term solar radiation calculations. Part 2: Impact on long-term solar irradiance predictions, Solar Energy 135 (2016) 625-632.

[36] J. Shen, N. Cao, Accurate inversion of tropospheric aerosol extinction coefficient profile by MieRaman lidar, Optik 184 (2019) 153-164.

[37] Peng Zhang, Houzhang Tan, Ruijie Cao, Yiwu Wang, Renhui Yuan, R. Han, Emission characteristics of particulate matter from coal-fired boilers in Xi'an city (In chinese), Environmental Engineering 36(9) (2018) 63-67.

[38] H. Yang, W. Tao, Y. Liu, M. Qiu, J. Liu, K. Jiang, K. Yi, Y. Xiao, S. Tao, The contribution of the Beijing, Tianjin and Hebei region's iron and steel industry to local air pollution in winter, Environmental Pollution 245 (2019) 1095-1106. 